\title{
Sensitive detection of glucagon aggregation using amyloid fibril-specific antibodies
}

\author{
Samuel D. Stimple ${ }^{1,2}$ | Sibel Kalyoncu ${ }^{3 *}$ | Alec A. Desai ${ }^{2}$ | Jesper E. Mogensen ${ }^{4} \mid$ \\ Lotte T. Spang $^{5}$ | Désirée J. Asgreen ${ }^{5}$ Arne Staby ${ }^{4}$ Peter M. Tessier ${ }^{1,2,6}{ }^{\infty}$
}

${ }^{1}$ Department of Pharmaceutical Sciences, Biointerfaces Institute, University of Michigan, Ann Arbor, MI

${ }^{2}$ Department of Chemical Engineering Biointerfaces Institute, University of Michigan, Ann Arbor, Ml

${ }^{3}$ Isermann Department of Chemical \& Biological Engineering, Center for Biotechnology \& Interdisciplinary Studies, Rensselaer Polytechnic Institute, Troy, NY

${ }^{4} \mathrm{CMC}$ Development, R\&D, Novo Nordisk A/S, Copenhagen, Denmark

${ }^{5}$ New Product Introduction, Product Supply, Novo Nordisk A/S, Copenhagen, Denmark

${ }^{6}$ Department of Biomedical Engineering, Biointerfaces Institute, University of Michigan, Ann Arbor, MI

\section{Correspondence}

Peter M. Tessier, Departments of Pharmaceutical Sciences, Chemical Engineering and Biomedical Engineering, Biointerfaces Institute, University of Michigan, B10-A179 NCRC, 2800 Plymouth Road, Ann Arbor, MI 48109

Email: ptessier@umich.edu

Present address

Sibel Kalyoncu, Izmir Biomedicine and

Genome Center, Izmir, Turkey.

Funding information

Novo Nordisk A/S; Albert M. Mattocks Chair

\begin{abstract}
Sensitive detection of protein aggregates is important for evaluating the quality of biopharmaceuticals and detecting misfolded proteins in several neurodegenerative diseases. However, it is challenging to detect extremely low concentrations $(<10 \mathrm{ppm})$ of aggregated protein in the presence of high concentrations of soluble protein. Glucagon, a peptide hormone used in the treatment of extreme hypoglycemia, is aggregation-prone and forms amyloid fibrils. Detection of glucagon fibrils using conformation-specific antibodies is an attractive approach for identifying such aggregates during process and formulation development. Therefore, we have used yeast surface display and magnetic-activated cell sorting to sort single-chain antibody libraries to identify antibody variants with high conformational specificity for glucagon fibrils. Notably, we find several high-affinity antibodies that display excellent selectivity for glucagon fibrils, and we have integrated these antibodies into a sensitive immunoassay. Surprisingly, the sensitivity of our assay-which involves direct (nonantibody mediated) glucagon immobilization in microtiter plates-can be significantly enhanced by pretreating the microtiter plates with various types of globular proteins before glucagon immobilization. Moreover, increased total concentrations of glucagon peptide also significantly improve the sensitivity of our assay, which appears to be due to the strong seeding activity of immobilized fibrils at high glucagon concentrations. Our final assay is highly sensitive (fibril detection limit of $\sim 0.5-1 \mathrm{ppm}$ ) and is $>20$ times more sensitive than detection using a conventional, amyloid-specific fluorescent dye (Thioflavin T). We expect that this type of sensitive immunoassay can be readily integrated into the drug development process to improve the generation of safe and potent peptide therapeutics.
\end{abstract}

KEYWORDS

aggregate, antibody, conformation, directed evolution, protein

\section{1 | INTRODUCTION}

There is wide-spread interest in using biologics-ranging from relatively small peptide hormones to large monoclonal antibodiesas drugs given their unique properties, including their high affinity and specificity for their targets and low toxicity and immunogenicity. In the area of polypeptide therapeutics, the glucose-regulated peptide glucagon has proven to be a valuable therapeutic agent that modulates blood glucose levels. Glucagon is produced through the tissue-specific posttranslational processing of preproglucagon 
(White \& Saunders, 1986). Glucagon is a first-line treatment in addressing extreme hypoglycemia, among other indications (HallBoyer, Zaloga, \& Chernow, 1984). It stimulates glycogenolysis and gluconeogenesis via binding to the glucagon receptor, resulting in a signal cascade that rapidly increases blood sugar levels (Unson, 2002). The important biological role of this peptide has motivated interest in using it for the treatment of extreme hypoglycemia in the clinic, and has made glucagon a molecule of interest (alongside insulin) for development of bihormonal pumps that manage blood sugar levels in individuals with type 1 diabetes (Castle et al., 2010; ElKhatib, Russell, Nathan, Sutherlin, \& Damiano, 2010; Russell et al., 2012, 2014; Steiner, Li, Hauser, \& Pohl, 2010).

A key challenge in developing biologics as therapeutics is that they display variable and difficult-to-predict levels of aggregation (Dobson, 1999), which can lead to the presence of aggregated species in the purified and formulated drug product (Onoue et al., 2004; Wang, 2005). For highly aggregation-prone biologics, concerns regarding batch-to-batch variability in drug quality and immunogenicity can greatly complicate the downstream stages of bioprocess development and quality assurance, while also presenting threats to patient safety. Indeed, native glucagon is well-known for displaying poor solubility and high propensity for aggregation into amyloid fibrils of diverse morphologies (De Jong, Incledon, Yip, \& DeFelippis, 2006; Dong, Hovgaard, Xu, Otzen, \& Besenbacher, 2006; Ghodke et al., 2012; Gratzer, Bailey, \& Beaven, 1967; Pedersen, 2010; Pedersen \& Otzen, 2008; Pedersen et al., 2006). For instance, glucagon fibril formation can occur rapidly, and its rate is highly dependent on the initial concentration of amyloid present in the sample. Consequently, reconstituted glucagon is generally only stable over short timeframes and must be solubilized immediately before use. Such challenges have led to significant efforts in optimizing formulations to minimize aggregation (Bakhtiani et al., 2015; Pohl, Li, Krasner, \& De Souza, 2015; Steiner et al., 2010; Ward et al., 2010), enhancing peptide stability and solubility through alterations in amino acid or chemical composition (Chabenne, DiMarchi, Gelfanov, \& DiMarchi, 2010), and developing assays that detect aggregates (or the propensity to form aggregates) using fluorescent dyes, intrinsic tryptophan fluorescence, and other techniques (Hovgaard Dong, Otzen, \& Besenbacher, 2007; Oliveira et al., 2009; Pedersen et al., 2006).

Despite this important progress, it remains extremely challenging to sensitively detect endogenous glucagon aggregates that are present at extremely low levels (e.g., $<10$ ppm). Such concentrations are typically too dilute for detection using conventional methods such as amyloid-specific dyes (e.g., Thioflavin T, ThT) and sizeexclusion chromatography without first stressing the samples to amplify the amount of aggregate. We reasoned that an enzymelinked immunosorbent assay (ELISA)-based method could be developed to achieve much more rapid and sensitive detection of glucagon amyloid fibrils than conventional methods without the need for stressing the samples to amplify the aggregates. Due to the lack of existing conformational antibodies specific for glucagon, we sought to generate such antibodies using in vitro antibody discovery methods that involve sorting single-chain antibody fragment (scFv) libraries using yeast surface display to identify variants with high affinity for aggregated glucagon and low affinity for soluble glucagon. Herein, we report the identification of amyloid-specific antibodies that recognize glucagon fibrils and demonstrate an ELISA method that is much more sensitive than conventional methods.

\section{MATERIALS AND METHODS}

\section{1 | Preparation of soluble and fibrillated glucagon}

Glucagon powder (Novo Nordisk A/S, Copenhagen, Denmark) was solubilized at a concentration of $10 \mathrm{~g} / \mathrm{L}$ in $10 \mathrm{mM} \mathrm{HCl}$ and sterilized by using $0.2 \mu \mathrm{m}$ filters (28145-501; VWR International, Radnor, PA). Glucagon was then diluted to a final concentration of $1 \mathrm{~g} / \mathrm{L}(50 \mathrm{mM}$ glycine, $\mathrm{pH}$ 2.5). Fibrils were assembled at $37^{\circ} \mathrm{C}$ with shaking ( $900 \mathrm{rpm}, 18 \mathrm{hr}$ ), and then recovered by ultracentrifugation at 221,000xg for $1 \mathrm{hr}$ at $4^{\circ} \mathrm{C}$ (Tube PC Thickwall, $1 \mathrm{ml}, 45237$; Thermo Fisher Scientific, Waltham, MA). Fibril pellets were washed once and then resuspended in either the original volume of buffer $(50 \mathrm{mM}$ glycine, $\mathrm{pH}$ 2.5) for ELISA analysis or phosphate buffered saline (PBS) for coupling to magnetic beads, sorting, and initial ELISA screening. Fibril concentrations were determined by bicinchoninic acid (BCA) or micro BCA assays (23225 or 23235; Thermo Fisher Scientific). Before use, fibrils were sonicated (FB-120 Sonic Dismembrator; Thermo Fisher Scientific) on ice for $30 \mathrm{~s}$ at $100 \%$ amplitude (3 cycles of $10 \mathrm{~s}$ on and $30 \mathrm{~s}$ off) to reduce fibril size and increase homogeneity, which is expected to improve their immobilization on magnetic beads and microtiter plates, as well as to disrupt fibril clumps that form during ultracentrifugation.

\section{2 | Fluorescence analysis of glucagon fibrils}

Soluble and fibrillar glucagon were separately diluted to a final concentration of $245 \mu \mathrm{M}$ (50 mM glycine, $\mathrm{pH} 2.5$ ). For tryptophan fluorescence emission scans, sample $(50 \mu \mathrm{l})$ was added to black 384 well plates (12566624; Thermo Fisher Scientific), and intrinsic fluorescence emission scans were performed from 300 to $500 \mathrm{~nm}$ $\left(\lambda_{\text {ex }}=280 \mathrm{~nm}\right)$. For ThT fluorescence emission scans, ThT was added to the samples at a final concentration of $4 \mu \mathrm{M}$ (final glucagon concentration of $200 \mu \mathrm{M})$. A $50 \mu \mathrm{l}$ sample of the peptide/ThT mixtures was added to the wells of black 384-well plates, and fluorescence emission scans were performed from 450 to $550 \mathrm{~nm}$ $\left(\lambda_{e x}=444 \mathrm{~nm}\right)$. All fluorescence readings were performed at room temperature using a BioTek Synergy Neo microplate reader.

\section{3 | Atomic force microscopy}

Glucagon fibrils were diluted to a concentration of $50 \mu \mathrm{M}$ in $50 \mathrm{mM}$ glycine (pH 2.5). A $10 \mu \mathrm{l}$ sample of glucagon fibrils was deposited on a $1 \times 1 \mathrm{~cm}$ sheet of Muscovite Mica (V-1 Quality, 71855-05; Electron Microscopy Sciences, Hatfield, PA) that was attached to a glass slide 
with double-sided tape. The sample was incubated on the mica (45 min), washed with $1 \mathrm{ml}$ of sterile deionized water, and imaged at room temperature using an Asylum Research Molecular Force Probe 3D. Tapping-mode (noncontact) imaging in air was used to determine the morphology of the fibrils. Image processing and analysis of the force data were conducted using the built-in features of MFP 3D software.

\subsection{Cloning of antibody variants}

Antibodies (scFvs) specific for glucagon fibrils were isolated using mutagenesis (Tiller, Chowdhury et al., 2017), yeast surface display and magnetic sorting using Dynabeads (Dynabeads M-280 Tosylactivated, 14203; Invitrogen, Carlsbad, CA) coated with immobilized fibrillar or soluble glucagon using methods related to those reported previously (Julian et al., 2019). Briefly, $8 \times 10^{7}$ beads were washed twice with $1 \mathrm{ml}$ of PBS. Soluble glucagon $(100 \mu \mathrm{g})$ was then coupled to the beads in $800 \mu \mathrm{l}$ of buffer $(50 \mathrm{mM}$ borate, $\mathrm{pH}$ 9.5) overnight $\left(4^{\circ} \mathrm{C}\right.$, no mixing). Fibrillar glucagon $(100 \mu \mathrm{g})$ was coupled in $800 \mu \mathrm{l}$ of PBS overnight at room temperature with end-over-end mixing. The beads were quenched by washing twice with PBS supplemented with $10 \mathrm{mM}$ glycine and then washed with PBS supplemented with $1 \mathrm{~g} / \mathrm{L}$ bovine serum albumin (BSA; PBS-B) before incubation with yeast. All positive selections were performed against fibrillar glucagon in PBS-B supplemented with $1 \%$ milk, and the negative selections were performed against soluble glucagon in PBS-B.

Following eight rounds of yeast sorting, the plasmid DNA for the enriched yeast libraries was recovered with the Zymoprep Yeast Plasmid Miniprep II Kit (D2004; Zymo Research, Irvine, CA). The isolated scFv genes were amplified with Phusion High-Fidelity DNA Polymerase (M0530L; New England Biolabs, Ipswich, MA), and cloned by standard DNA restriction and ligation methods. The scFv genes were cloned between the $\mathrm{Ncol}$ and Notl restriction sites of antiNotch1_E6-pBIOCAM5, which was a gift from John McCafferty (Plasmid \# 39344, Addgene, Watertown, MA; Falk et al., 2012). The resulting constructs encoded a bivalent scFv-human Fc fusion protein containing C-terminal 6xHis and 3xFLAG tags, and their DNA sequences were determined by Sanger sequencing.

\subsection{Antibody expression and purification}

The antibodies were expressed transiently in adherent HEK 293T cells (CRL-3216; ATCC, Manassas, VA) using Invitrogen Lipofectamine 2000 Transfection Reagent (11668019; Thermo Fisher Scientific), as described previously (Julian et al., 2019; Rabia, Zhang, Ludwig, Julian, \& Tessier, 2019; Tiller, Li et al., 2017). Briefly, cells were cultured in $\sim 15 \mathrm{ml}$ of Dulbecco's Modified Eagle's Medium (DMEM) culture media (10569-044; Thermo Fisher Scientific) supplemented with $10 \%$ fetal bovine serum (35010CV; Corning, Corning, NY) and 1\% penicillin/streptomycin (15140122; Thermo Fisher Scientific) in $75 \mathrm{~cm}^{2}$ cell culture flasks (0030711122; Eppendorf, Hamburg, Germany) until reaching $~ 80 \%$ confluence. Lipofectamine $2000(20 \mu \mathrm{g} / \mathrm{flask})$ and plasmid DNA (8 $\mu \mathrm{g} / \mathrm{flask})$ were separately added to $0.5 \mathrm{ml}$ OPTI-MEM media (31985-062; Thermo Fisher Scientific) and incubated for $10 \mathrm{~min}$. Lipofectamine and DNA were then mixed and allowed to incubate for $30 \mathrm{~min}$. Spent media in the flasks was replaced with the media ( $15 \mathrm{ml}$ of DMEM) containing DNA and lipofectamine, and the cells were cultured for 3-4 days at $37^{\circ} \mathrm{C}$ under $5 \% \mathrm{CO}_{2}$. The media containing secreted antibody was harvested and centrifuged at 2,500xg for $5 \mathrm{~min}$ to remove the cells.

The secreted antibodies were purified via Protein A (20334; Thermo Fisher Scientific). Culture media was incubated with $1 \mathrm{ml}$ (50\% slurry) of Protein A agarose resin overnight at $4^{\circ} \mathrm{C}$ on a rocking plate. The resin was collected by vacuum filtration in a $10 \mathrm{ml}$ purification column (89898; Thermo Fisher Scientific), and the resin was washed with $100 \mathrm{ml}$ of PBS. The antibodies were then incubated with $1.5 \mathrm{ml}$ of $0.1 \mathrm{M}$ glycine buffer $(\mathrm{pH} 2.5)$ for $15 \mathrm{~min}$ and eluted via centrifugation. The $\mathrm{pH}$ of the eluted protein solutions was adjusted to near-neutral $\mathrm{pH}$ by addition of one-tenth of the elution volume of potassium phosphate $(1 \mathrm{M})$, and the antibodies were buffer exchanged into PBS using Zeba Spin Desalting Columns (89891; Thermo Fisher Scientific). Protein concentrations were determined using the micro BCA assay or by measuring absorbance at $280 \mathrm{~nm}$ (extinction coefficients of $168,460-205,360 \mathrm{M}^{-1} \mathrm{~cm}^{-1}$ ) before use, and protein purity was confirmed by sodium dodecyl sulfate-polyacrylamide gel electrophoresis.

\section{6 | Antibody binding analysis}

\subsection{1 | Initial screening of antibodies}

Glucagon was diluted to $25 \mu \mathrm{M}$ in buffer (50 mM glycine, $\mathrm{pH} 2.5$ ) for preparing the soluble peptide or in PBS for preparing the fibrillar peptide, and $100 \mu \mathrm{l}$ of sample was incubated overnight at $4^{\circ} \mathrm{C}$ in Nunc MaxiSorp 96-well ELISA plates (439454; Thermo Fisher Scientific). All primary and secondary antibody binding steps were performed in PBS supplemented with $0.1 \%$ Tween 20 and $1 \mathrm{~g} / \mathrm{L} \mathrm{BSA}$ (PBST-B), and the sample volumes were $100 \mu$ l (unless otherwise specified). Wash steps between incubations were performed three times with PBS $(300 \mu \mathrm{l})$. The antibodies were diluted to a concentration of $0.5 \mathrm{nM}$ in PBST-B and incubated with immobilized glucagon for $1 \mathrm{hr}$ at room temperature. After washing, secondary antibody (Invitrogen Goat anti-Human IgG Fc HRP-conjugate, A18817; Thermo Fisher Scientific) was diluted 1:1000 (stock concentration of $0.5 \mathrm{mg} / \mathrm{mL}$ ) into PBST-B and incubated for $1 \mathrm{hr}$ at room temperature. Antibody binding was detected by addition of $100 \mu$ l of 1-Step UItra-TMB ELISA Substrate Solution (34028; Thermo Fisher Scientific) to each well, and reactions were quenched with $2 \mathrm{M}$ sulfuric acid $(100 \mu \mathrm{l})$ after formation of the colored product. For all reported assays, reactions were quenched after 3-5 min. The absorbance of each well was measured at $450 \mathrm{~nm}$ using a Biotek Synergy Neo microplate reader. Reported signal ratios represent the ratio of the ELISA signal for wells coated with fibrillar glucagon relative to signal for wells coated with soluble glucagon at an equivalent concentration.

Binding curves for the most promising antibodies were generated using the following procedure. First, soluble or fibrillar glucagon was 
diluted to $2.5 \mu \mathrm{M}(50 \mathrm{mM}$ glycine, $\mathrm{pH} 2.5$ ), and $100 \mu$ l of sample was incubated overnight at $4^{\circ} \mathrm{C}$ in Nunc MaxiSorp 96-well ELISA plates. After washing, the antibodies were added to the wells at a range of concentrations in PBST-B. Antibodies were incubated for $1 \mathrm{hr}$ at room temperature. The sequence specificity of the antibodies for glucagon fibrils was examined using human A $1-42$, $\alpha$-synuclein, and islet amyoid polypeptide (IAPP) fibrils. The respective antigens were immobilized to the plates overnight at $4^{\circ} \mathrm{C}$ at a concentration of $2.5 \mu \mathrm{M}$. After washing, the antibodies were incubated at concentrations of 0.5 and $5 \mathrm{nM}$ in PBST-B for $1 \mathrm{hr}$ at room temperature. Secondary antibody binding and substrate development/ quenching were performed as described above.

\subsection{2 | Screening assay conditions for optimal antibody sensitivity}

Three different types of ELISA plates and three primary antibody binding solutions were used to study the robustness of the ELISA assay. Soluble and fibrillar glucagon were separately immobilized $(50 \mathrm{mM}$ glycine, $\mathrm{pH}$ 2.5) for $2 \mathrm{hr}$ (room temperature) using a range of peptide concentrations (0.0005-25 $\mu \mathrm{M}$ ) in MaxiSorp (439454; Thermo Fisher Scientific), medium binding (655080; Greiner Bio-One, Kremsmünster, Austria), and high binding (655081; Greiner Bio-One) 96-well ELISA plates. After washing, antibody $(0.5 \mathrm{nM})$ was added for fibril detection.

The effect of solution conditions during the primary antibody binding step of the immunoassay was also investigated. Soluble and fibrillar glucagon were immobilized $(2.5 \mu \mathrm{M})$ in the wells of MaxiSorp plates overnight at $4^{\circ} \mathrm{C}$. After washing, primary antibodies were incubated at a range of concentrations $(0.5,5$, and $50 \mathrm{nM}$ ) with the immobilized peptides for $1 \mathrm{hr}$ at room temperature in (a) PBS supplemented with $0.1 \%$ Tween 20 and $1 \mathrm{~g} / \mathrm{L}$ BSA (PBST-B), (b) PBS supplemented with $0.1 \%$ Tween 20 and $100 \mathrm{~g} / \mathrm{L}$ BSA, and (c) PBS supplemented with $0.1 \%$ Tween 20, $1 \mathrm{~g} / \mathrm{L} \mathrm{BSA}$, and $0.1 \%$ milk. Secondary antibody binding and substrate addition and quenching were performed as previously described.

\subsection{3 | Detection of glucagon fibrils in mixtures of soluble and fibrillar glucagon}

Mixtures of fibrillar and soluble glucagon containing a wide range of initial concentrations of fibril were prepared at a total glucagon concentration of $200 \mu \mathrm{M}$ (50 mM glycine, $\mathrm{pH} 2.5)$. The mixtures were incubated in Nunc MaxiSorp 96-well plates and allowed to bind for $2 \mathrm{hr}$ (room temperature). After washing, the primary antibodies $(0.5 \mathrm{nM})$ were incubated for $1 \mathrm{hr}$ at room temperature (PBST-B). Secondary binding and substrate development and quenching were performed as previously described. For ThT detection of glucagon fibrils, mixtures were prepared at a total concentration of $245 \mu \mathrm{M}$ (50 mM glycine, $\mathrm{pH} 2.5$ ) and incubated in microcentrifuge tubes for $2 \mathrm{hr}$. ThT was added (final concentrations of 4,40 , and $400 \mu \mathrm{M}$ ) while maintaining the final glucagon concentration at $200 \mu \mathrm{M}$. After $5-10 \mathrm{~min}, 50 \mu \mathrm{l}$ of sample was added to black 384-well plates (Fisherbrand 384 Well Polystyrene Plates; 12566624; Thermo Fisher
Scientific), and ThT fluorescence $\left(\lambda_{e x}=444 \mathrm{~nm}\right.$ and $\left.\lambda_{e m}=482 \mathrm{~nm}\right)$ values were measured using a Biotek Synergy Neo microplate reader.

\subsubsection{Optimization of ELISA microtiter plates by pretreatment with globular proteins}

Nunc MaxiSorp plates were coated with four different globular proteins of varying isoelectric point (BSA [pl of $\sim 4.7$ ], ovalbumin [pl of $\sim 4.5$ ], lysozyme [pl of $\sim 11$ ], and avidin [pl of $\sim 10]$ ). Proteins were dissolved at $1 \mathrm{~g} / \mathrm{L}$ in PBS, filtered, and immobilized overnight at $4^{\circ} \mathrm{C}$. After washing, mixtures of soluble and fibrillar glucagon (total peptide concentration of $200 \mu \mathrm{M}$ ) were incubated in the plates for $2 \mathrm{hr}$ at room temperature. Surface-immobilized fibrils were detected by incubation with primary antibody $(0.5 \mathrm{nM})$ in PBST-B for $1 \mathrm{hr}$ at room temperature, and antibody detection was performed as described above.

\subsubsection{Effect of glucagon concentration on ELISA sensitivity}

MaxiSorp plates were coated with $1 \mathrm{~g} / \mathrm{L}$ BSA (PBS, filtered) overnight at $4^{\circ} \mathrm{C}$. Mixtures of soluble and fibrillar glucagon were prepared in $50 \mathrm{mM}$ glycine $(\mathrm{pH} 2.5)$ at a total glucagon concentration of 2,20 , and $200 \mu \mathrm{M}$. The mixtures were incubated in well plates for $2 \mathrm{hr}$ at room temperature, the plates were washed, and fibrils were detected using primary antibody $(0.5 \mathrm{nM})$ in PBST-B, with secondary incubation and substrate addition and quenching performed as described above.

\section{3 | RESULTS}

\section{1 | Identification of conformational antibodies specific for glucagon amyloid fibrils}

Our first step toward selection of conformational antibodies against glucagon amyloid fibrils involved antigen assembly and characterization for subsequent use during antibody selection. Glucagon peptide (3483 Da) is only sparingly soluble at neutral $\mathrm{pH}$, which led us to evaluate other conditions for forming fibrils in a well defined manner. We chose to assemble fibrils at $\mathrm{pH} 2.5$ (50 mM glycine) based on previous work that demonstrated reproducible fibril formation at these conditions, and also because lyophilized glucagon powder is reconstituted at acidic $\mathrm{pH}$ for pharmaceutical administration (Pedersen et al., 2006). The fibrils formed over a period of $18 \mathrm{hr}$ and were recovered via ultracentrifugation. The properties of the resulting aggregates were studied using an amyloid-specific dye (ThT), intrinsic tryptophan fluorescence, and atomic force microscopy (AFM; Figure 1). The amyloid nature of the fibrils was confirmed by relatively high ThT fluorescence (Figure 1a), a significant blue-shift in the intrinsic tryptophan fluorescence emission maxima relative to soluble glucagon (Figure 1b), and fibril-like morphology as revealed by AFM (Figure 1c).

Next, we sought to screen for antibodies with selective affinity for glucagon fibrils. The antibody library that was used for yeast 
(a)

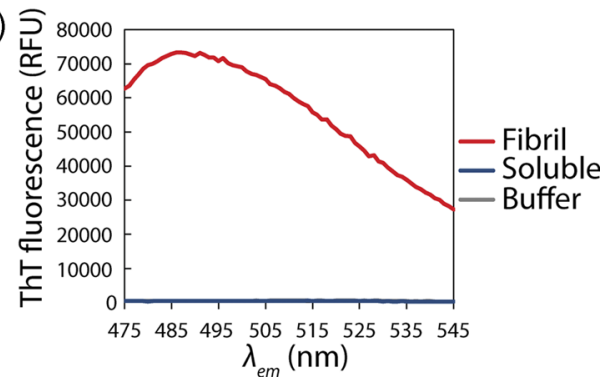

(b)

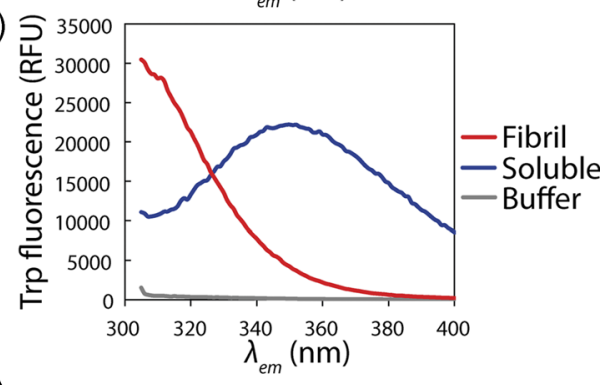

(c)

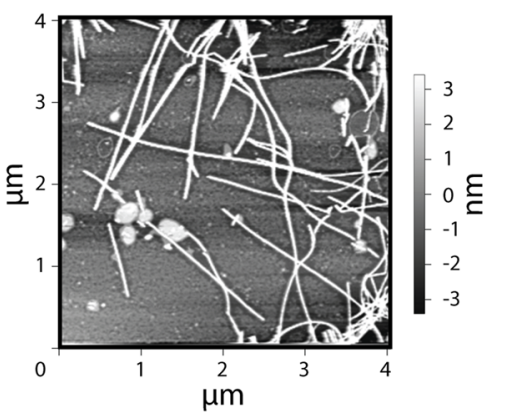

FIGURE 1 Characterization of glucagon fibril assembly. Glucagon fibrils were assembled at a concentration of $1 \mathrm{~g} / \mathrm{L}$ in $50 \mathrm{mM}$ glycine $(\mathrm{pH} 2.5)$ using agitation $(900 \mathrm{rpm})$ at $37^{\circ} \mathrm{C}$. The amyloid nature of the resulting peptide aggregates was evaluated using (a) Thioflavin $T$ fluorescence (emission scans, $\lambda_{e x}=444 \mathrm{~nm}$ ), (b) tryptophan (intrinsic) fluorescence (emission scans, $\lambda_{e x}=280 \mathrm{~nm}$ ), and (c) atomic force microscopy [Color figure can be viewed at wileyonlinelibrary.com] surface display was prepared using the variable regions from 4D5 (Albanell \& Baselga, 1999) with diversification at 15 sites in heavy chain CDR3 (HCDR3; Tiller, Chowdhury et al., 2017). The DNA encoding the antibody library was fused to a yeast cell-surface protein (Aga2). Antibodies expressed on the surface of yeast were sorted via negative selections against magnetic beads coated with soluble glucagon, while positive sorts were performed against beads coated with fibrillar glucagon.

Following eight rounds of iterative negative and positive sorting $(\mathrm{pH} 7.4)$, the enriched antibody library was recovered, cloned as scFvFc antibodies, and sequenced. We identified 23 unique antibodies, which were subsequently expressed in HEK 293T and purified using Protein A chromatography. Next, we examined the conformational specificity of the antibodies by immobilizing soluble and fibrillar glucagon $(25 \mu \mathrm{M})$ in 96-well ELISA microtiter plates (Figure 2). Binding of the antibodies was assessed at a relatively low concentration $(0.5 \mathrm{nM})$. A majority of the 23 antibodies displayed high degrees of conformational specificity for glucagon fibrils relative to the soluble peptide, while also displaying low levels of background binding to uncoated ELISA plates.

The conformational specificity of four of the most promising antibodies was evaluated at neutral $\mathrm{pH}$ in more detail by testing a range of primary antibody concentrations (Figure 3). Even at high antibody concentrations (> $100 \mathrm{nM}$ ), we observed high conformational specificity, with concentrations between 0.5 and $5 \mathrm{nM}$ providing the greatest discrimination between the soluble and fibrillar forms of glucagon. Notably, the four antibody variants performed similarly in this experiment ( $\mathrm{EC}_{50}$ values of $0.28-0.4 \mathrm{nM}$ for glucagon fibrils), which led us to further assess their binding to other amyloid species (human A 1 42, $\alpha$-synuclein, and IAPP fibrils; Figure S1). Unexpectedly, we observed that the antibody variants recognized some of the nonglucagon fibrils. Relative to glucagon fibrils, the antibodies displayed increased binding to IAPP fibrils, reduced binding to A $1-42$ fibrils, and little binding to $\alpha$-synuclein fibrils. It was unclear why the glucagon antibodies reacted with some nonglucagon amyloids and not others, and it is not possible

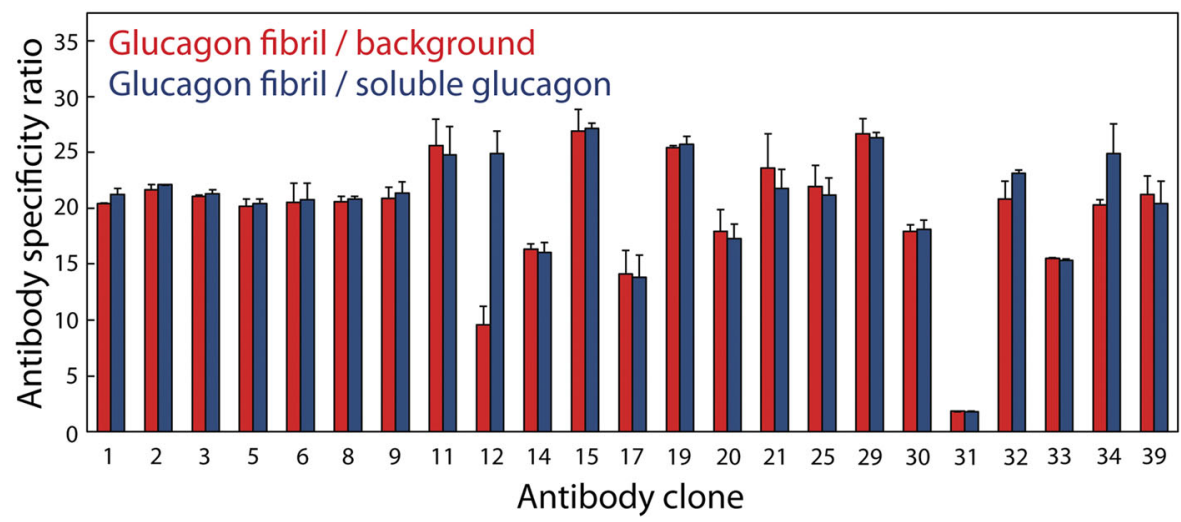

FIGURE 2 Evaluation of the conformational specificity of a panel of glucagon antibodies. Soluble and fibrillar glucagon were separately immobilized overnight in Nunc MaxiSorp ELISA plates at a concentration of $25 \mu \mathrm{M}\left(4^{\circ} \mathrm{C}\right)$, and the specificity of each antibody $(0.5 \mathrm{nM})$ for fibrillar glucagon relative to soluble peptide was determined. The reported specificity ratios are the raw ELISA signals for antibodies binding to immobilized glucagon fibrils relative to either immobilized soluble glucagon (blue) or nontreated microtiter plates (background, red). Error bars represent standard errors. ELISA: enzyme-linked immunosorbent assay [Color figure can be viewed at wileyonlinelibrary.com] 
- Glucagon, fibril • Glucagon, soluble • Buffer
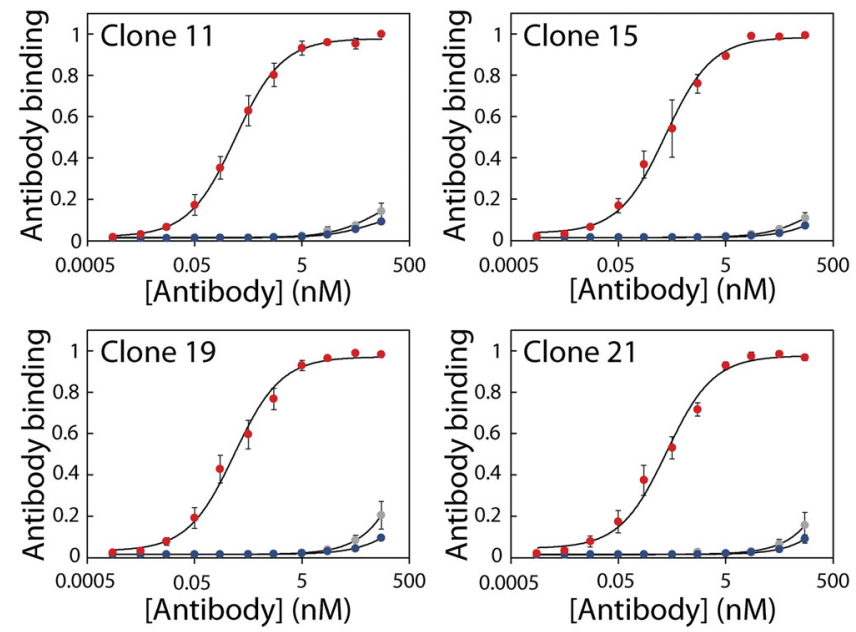

FIGURE 3 Characterization of the concentration-dependent binding of glucagon antibodies. The specificity of antibodies for glucagon fibrils relative to soluble glucagon was evaluated using glucagon immobilized in MaxiSorp plates $(2.5 \mu \mathrm{M})$. The reported values are normalized ELISA signals. Average values for three independent experiments are reported, while the error bars are standard errors. The data are fit using three-parameter Hill equations. ELISA: enzyme-linked immunosorbent assay [Color figure can be viewed at wileyonlinelibrary.com]

to predict the antibody reactivity with other amyloidogenic polypeptides without further experimental analysis. Collectively, these results demonstrate that the glucagon antibodies recognize glucagon fibrils with high conformational specificity and cross-react with a subset of non-glucagon amyloids.

We next sought to evaluate the impact of various factors on the the performance of our immunoassay. Considering that glucagon is a relatively small peptide and different types of ELISA plates are optimized for immobilization of distinct sizes, classes, and types of biomolecules, we sought to examine if specific types of ELISA plates offered improved assay sensitivity. However, we observed similar performance for three types of ELISA plates (Figure S2), suggesting that assay performance was weakly influenced by the plate surface. We also evaluated the impact of the solution conditions used during antibody binding on assay performance (Figure S3). Addition of high concentrations of BSA $(100 \mathrm{mg} / \mathrm{ml})$ during antibody binding led to relatively small effects on assay performance. However, addition of $0.1 \%$ milk during primary antibody binding inhibited recognition of glucagon fibrils. These results indicate that the antibodies recognize glucagon amyloid fibrils via molecular interactions that can be blocked by the components in milk.

\section{2 | Optimization of ELISA detection of glucagon fibrils}

To mimic detection of low levels of endogenous glucagon amyloids in the final drug product, we next sought to test if our antibodies could detect low concentrations of glucagon fibrils in the presence of a

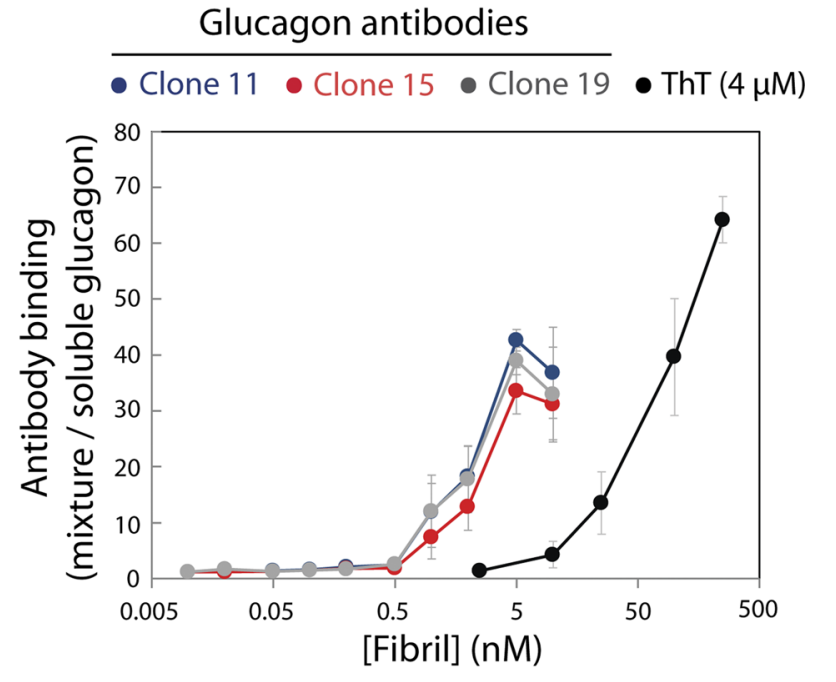

FIGURE 4 Comparison of glucagon amyloid detection using conformational antibodies and an amyloid-specific fluorescent dye (ThT). Antibody detection was performed using mixtures of soluble and fibrillar glucagon prepared at a total glucagon concentration of $200 \mu \mathrm{M}$ and immobilized in ELISA plates for $2 \mathrm{hr}$. ThT detection $(4 \mu \mathrm{M}$ ThT) was performed for mixtures of soluble and fibrillar glucagon prepared at a total glucagon concentration of $245 \mu \mathrm{M}$, incubated in microcentrifuge tubes for $2 \mathrm{hr}$, and diluted to a final glucagon concentration of $200 \mu \mathrm{M}$. For antibody detection, the values represent the mean for four independent experiments. For ThT detection, the values represent the mean for three independent experiments. The reported values for antibody and ThT detection of glucagon fibrils are normalized to the values obtained for soluble glucagon, and the error bars represent standard errors. ELISA: enzyme-linked immunosorbent assay [Color figure can be viewed at wileyonlinelibrary.com]

large excess of soluble glucagon (Figure 4). Therefore, we prepared mixtures of fibrillar and soluble glucagon containing low initial concentrations of fibril $(0-10 \mathrm{nM})$ at total glucagon concentrations of $200 \mu \mathrm{M}(\sim 0.7 \mathrm{~g} / \mathrm{L})$. These mixtures were incubated in ELISA plates for $2 \mathrm{hr}$ at room temperature. Encouragingly, wells incubated with glucagon samples initially containing $\geq 1 \mathrm{nM}$ of fibril gave rise to detectable antibody binding signals. For comparison, fibril/soluble glucagon mixtures were prepared and incubated with the amyloidspecific fluorescent dye ThT $(2 \mathrm{hr}$, final glucagon concentration of $200 \mu \mathrm{M}$ after addition of ThT). Importantly, ThT fluorescence above background was only detected at initial glucagon fibril concentrations $\geq \sim 10 \mathrm{nM}$ (Figure 4). These results demonstrate that our initial immunoassay is an order of magnitude more sensitive than a conventional amyloid detection assay. The concentration of ThT also impacted the sensitivity of glucagon amyloid detection, as we find concentrations of ThT $>40 \mu \mathrm{M}$ reduced sensitivity (Figure S4).

We reasoned that the sensitivity of our ELISA assay could be enhanced by using our antibodies as capture reagents in a sandwich ELISA format. However, our initial efforts at developing a sandwich ELISA revealed that glucagon fibrils were efficiently immobilized even if the ELISA plates were first blocked (data not shown). This interesting result led us to explore whether the surface of the ELISA plates could be 
optimized for fibril capture by pretreatment with different globular proteins before incubation with glucagon (Figure 5). Four different globular proteins with varying isoelectric points (BSA, pl of 4.7 ; ovalbumin, pl of $\sim 4.5$; lysozyme, pl of $\sim 11$; and avidin, pl of $\sim 10$ ) were used to treat the MaxiSorp plates before incubation with the mixtures of soluble and fibrillar glucagon. Relative to untreated plates, pretreatment with BSA and ovalbumin significantly improved assay sensitivity ( $\sim 5$-fold and $\sim 2$-fold increases in sensitivity, respectively). In contrast, pretreatment with lysozyme led to modest improvements and pretreatment with avidin decreased assay performance.

Finally, we evaluated the performance of our optimized assay as a function of the total glucagon concentration (Figure 6). BSA-treated plates were used to immobilize glucagon mixtures at three different total glucagon concentrations $(2,20$, and $200 \mu \mathrm{M})$, and the assay signal was compared for data points collected at the same initial fibril concentrations. We find that 10 -fold increases in total peptide concentration correspond to $\sim 10$-fold increases in assay sensitivity (Figure 6a). This result is likely due to enhanced fibril seeding at high glucagon concentrations. We also analyzed the results in terms of the percentage of fibril initially present in the sample mixture (Figure 6b). These results demonstrate that our optimized assay is capable of detecting extremely low (0.5-1 ppm) levels of glucagon fibrils that are far more dilute than can be detected using conventional (Thioflavin $\mathrm{T})$ methods ( $50 \mathrm{ppm})$.

\section{4 | DISCUSSION}

We have reported the discovery of a panel of conformational antibodies that recognize glucagon amyloids with high conformational specificity, as well as the optimization of an ELISA for sensitive detection of aggregates. Interestingly, our antibodies also cross-react with a subset of fibrils of other amyloidogenic polypeptides. While antibody sequence promiscuity would normally represent a concern during the development of a sensitive immunoassay, antibody recognition of different types of amyloids does not present an issue for detection of glucagon fibrillation in purified and formulated drug product. These results also raise the intriguing possibility that our antibodies may recognize conserved amyloid structural motifs, such as $\beta$-sheets or an amyloid-specific arrangement of the peptide backbone. This would be consistent with previous identification of conformational antibodies that recognize a broad range of prefibrillar or fibrillar conformers formed by different amyloidogenic polypeptides (Hrncic et al., 2000; Isas et al., 2010; Kayed \& Glabe, 2006; Kayed et al., 2003, 2007; O'Nuallain \& Wetzel, 2002; Wu et al., 2010). Interestingly, glucagon itself is known to form at least five distinct morphologies of amyloids that differ in their biophysical properties and ThT staining (De Jong et al., 2006; Gratzer et al., 1967; Pedersen, 2010; Pedersen \& Otzen, 2008; Pedersen et al., 2006). Consequently, antibodies capable of recognizing different types of glucagon fibrils likely to form during processing and storage would provide a more comprehensive analysis of glucagon product quality. We are currently working to understand which types of glucagon fibrils are recognized in our ELISA method.

We also observed a striking enhancement of ELISA sensitivity ( 100-fold) when fibrils are present in glucagon samples containing high concentrations of soluble glucagon. Using untreated MaxiSorp microtiter plates, the antibodies recognized purified, immobilized glucagon fibrils at concentrations $\geq 100 \mathrm{nM}$, but detected fibrils in

\section{Glucagon antibodies}

\begin{tabular}{|c|c|}
\hline - Clone $11 \bullet$ Clone $15 \bullet$ Clone 19 & -- Clone 11 --Clone 15 --Clone 19 \\
\hline Preblocked plates & Control plates \\
\hline
\end{tabular}

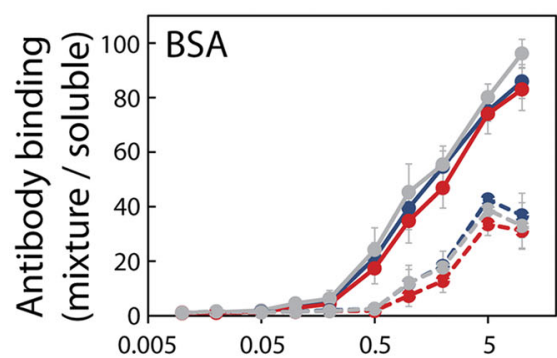

[Fibril] (nM)

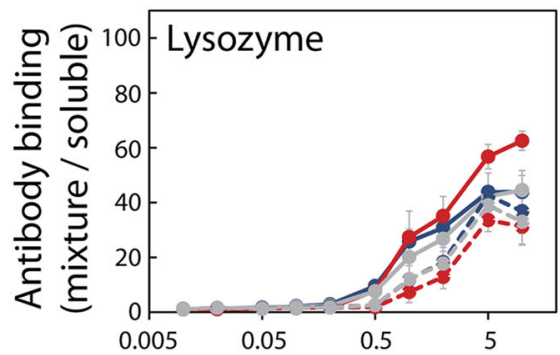

[Fibril] (nM)

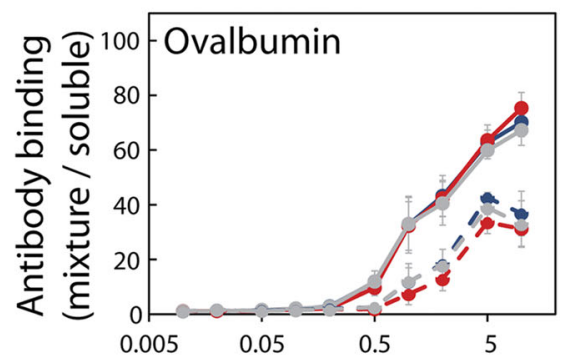

[Fibril] (nM)

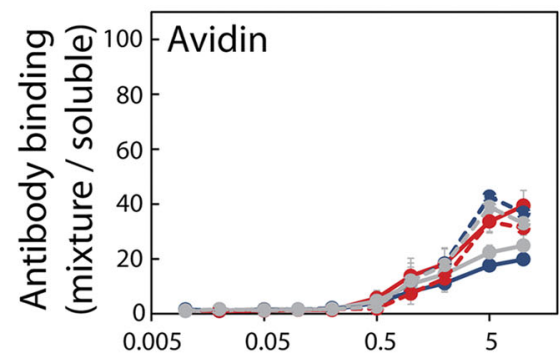

[Fibril] (nM)
FIGURE 5 Preblocking microtiter plates with globular proteins before glucagon immobilization enhances ELISA sensitivity. The performance of antibody detection of glucagon fibrils was compared using control (untreated) ELISA plates (dashed lines) and plates preblocked with four different globular proteins (solid lines) before glucagon sample incubation. The reported values represent the mean for at least three independent experiments, and error bars are standard errors. BSA: bovine serum albumin; ELISA: enzyme-linked immunosorbent assay [Color figure can be viewed at wileyonlinelibrary.com] 


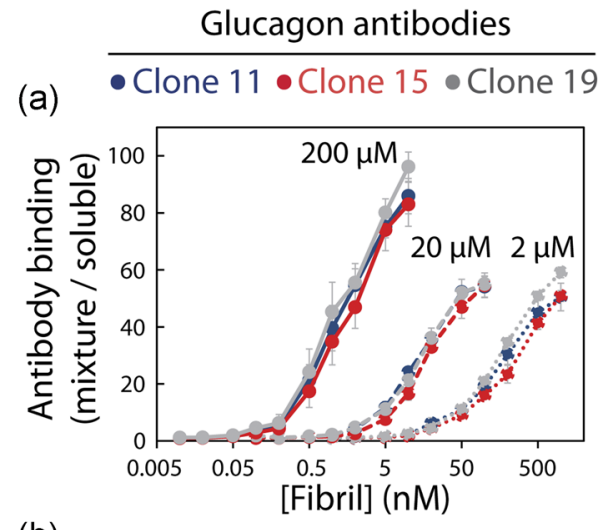

(b)

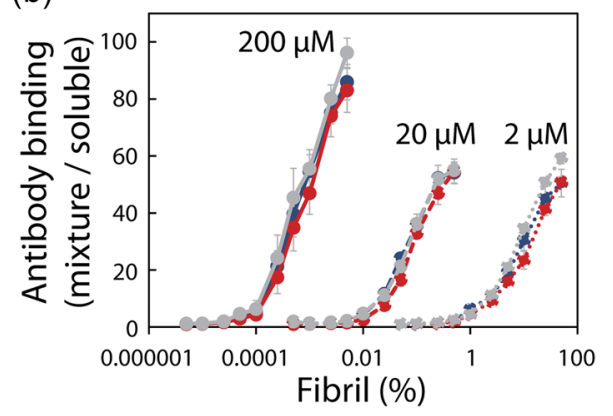

FIGURE 6 ELISA sensitivity is strongly dependent on the total glucagon peptide concentration. Mixtures of soluble and fibrillar glucagon were prepared at a range of concentrations (2, 20, and $200 \mu \mathrm{M})$ and contained a range of initial fibril concentrations. The glucagon mixtures were incubated in ELISA plates pretreated with BSA ( $2 \mathrm{hr}$ ) and detected using glucagon antibodies $(0.5 \mathrm{nM})$. The normalized ELISA absorbance values are reported for samples containing glucagon fibrils relative to soluble glucagon (control). The results of the assay are reported as a function of the (a) initial fibril concentration and (b) initial percentage of fibril. Reported values represent the mean for at least four independent experiments, and the error bars are standard errors. ELISA: enzyme-linked immunosorbent assay [Color figure can be viewed at wileyonlinelibrary.com]

mixtures with soluble peptide at much lower initial concentrations (as low as $\sim 1 \mathrm{nM}$ ). This finding suggests that extremely low fibril concentrations are efficient at seeding during short incubation times ( $2 \mathrm{hr}$ ), even without agitation. It is possible that (a) fibrils are immobilized and then are amplified via seeding, (b) fibrils are amplified via seeding in solution and then immobilized or (c) fibril seeding occurs both in solution and after immobilization. Regardless of the exact mechanism, it is likely that glucagon fibril seeding amplifies the detection sensitivity of our ELISA method.

Another contributing factor to the sensitivity of our assay is that glucagon fibrils were immobilized even when we first preblocked the ELISA plate with globular proteins. Notably, preblocking the plates with acidic proteins (BSA and ovalbumin, pls of $\sim 4.5-4.7$ ) improved assay performance, while basic proteins (lysozyme and avidin, pls $>10$ ) had little or negative impacts. The mechanism through which acidic proteins such as BSA enhance the ELISA signal remains unclear. BSA may improve immobilization of glucagon fibrils and/or reduce immobilization of soluble glucagon. It is notable that the glucagon samples were immobilized at $\mathrm{pH} 2.5$, which is well below the isoelectric points of BSA ( $\mathrm{pl}$ of 4.7 ) and glucagon ( $\mathrm{pl}$ of $~ 7.1$ ). Therefore, electrostatic interactions do not appear to explain the mechanism by which BSA and ovalbumin improve assay performance. Alternatively, nonelectrostatic interactions-such as hydrophobic interactions-between the albumins and glucagon fibrils may promote glucagon fibril immobilization relative to soluble glucagon immobilization. Regardless of the exact mechanism, it is clear that albumins modify the microtiter plate surface in a manner that enhances detection sensitivity, and this finding may be valuable for improving the detection of other amyloid-forming proteins in related types of ELISAs.

Finally, it is important to consider the practical implications of using our ELISA method for detecting glucagon aggregation relative to the conventional method (ThT fluorescence). Most previous studies using ThT to detect low levels of amyloid require agitation and long incubations (hours to days) to enhance fibril seeding and amplification of pre-existing aggregates (Pedersen \& Otzen, 2008; Pedersen et al., 2006). The need for agitation over long times is likely linked to the well-known problems with poor reproducibility of ThT assays. Our approach requires relatively short incubation times ( $2 \mathrm{hr}$ ) without agitation, which results in increased reproducibility. Our future work aims to improve antibody affinity to further enhance the sensitivity of the assay for detecting endogenous glucagon aggregates without the need for first amplifying the aggregates.

\section{5 | CONCLUSIONS}

Protein aggregation is a critical concern during the manufacture, formulation, and storage of a wide range of biopharmaceuticals (Lowe et al., 2011; Perchiacca \& Tessier, 2012; Shire, 2009). Therefore, it is particularly important to develop analytical methods and reagents for analysis of biopharmaceutical product quality for aggregation-prone polypeptides. We expect that our discovery of antibodies that recognize glucagon amyloid fibrils with high conformational specificity will improve the detection of aggregates using fast, simple, and reproducible ELISA methods. Our assay is much more sensitive than conventional (ThT) methods and does not require agitation to amplify pre-existing aggregates. Importantly, we find that glucagon fibril detection can be enhanced by pretreating ELISA plates with globular proteins and that fibril seeding during antigen immobilization greatly improves assay sensitivity. We expect that additional future research will enable even greater improvements in detection sensitivity and lead to extremely sensitive detection of peptide aggregates during the drug development process.

\section{ACKNOWLEDGMENTS}

We thank members of the Tessier lab for their helpful suggestions. This work was supported by Novo Nordisk A/S, and the Albert M. Mattocks Chair (to P.M.T). 


\section{CONFLICT OF INTERESTS}

J. E. M., A. S., D. J. A., and L. S. are employees of Novo Nordisk A/S. P. $M$. T. has received honorarium and consulting fees from Novo Nordisk A/S.

\section{ORCID}

Peter M. Tessier (ID http://orcid.org/0000-0002-3220-007X

\section{REFERENCES}

Albanell, J., \& Baselga, J. (1999). Trastuzumab, a humanized anti-HER2 monoclonal antibody, for the treatment of breast cancer. Drugs Today, 35(12), 931-946.

Bakhtiani, P. A., Caputo, N., Castle, J. R., El Youssef, J., Carroll, J. M., David, L. L., ... Ward, W. K. (2015). A novel, stable, aqueous glucagon formulation using ferulic acid as an excipient. Journal of Diabetes Science and Technology, 9(1), 17-23. https://doi.org/10.1177/ 1932296814552476

Castle, J. R., Engle, J. M., El Youssef, J., Massoud, R. G., Yuen, K. C. J., Kagan, R., \& Ward, W. K. (2010). Novel use of glucagon in a closedloop system for prevention of hypoglycemia in type 1 diabetes. Diabetes Care, 33(6), 1282-1287. https://doi.org/10.2337/dc09-2254

Chabenne, J. R., DiMarchi, M. A., Gelfanov, V. M., \& DiMarchi, R. D. (2010). Optimization of the native glucagon sequence for medicinal purposes. Journal of Diabetes Science and Technology, 4(6), 1322-1331. https:// doi.org/10.1177/193229681000400605

De Jong, K. L., Incledon, B., Yip, C. M., \& DeFelippis, M. R. (2006). Amyloid fibrils of glucagon characterized by high-resolution atomic force microscopy. Biophysical Journal, 91(5), 1905-1914. https://doi.org/10. 1529/biophysj.105.077438

Dobson, C. M. (1999). Protein misfolding, evolution and disease. Trends in Biochemical Sciences, 24(9), 329-332.

Dong, M., Hovgaard, M. B., Xu, S., Otzen, D. E., \& Besenbacher, F. (2006). AFM study of glucagon fibrillation via oligomeric structures resulting in interwoven fibrils. Nanotechnology, 17(16), 4003-4009. https://doi. org/10.1088/0957-4484/17/16/001

El-Khatib, F. H., Russell, S. J., Nathan, D. M., Sutherlin, R. G., \& Damiano, E. R. (2010). A bihormonal closed-loop artificial pancreas for type 1 diabetes. Science Translational Medicine, 2(27), 27ra27. https://doi.org/ 10.1126/scitransImed.3000619

Falk, R., Falk, A., Dyson, M. R., Melidoni, A. N., Parthiban, K., Young, J. L., ... McCafferty, J. (2012). Generation of anti-Notch antibodies and their application in blocking Notch signalling in neural stem cells. Methods, 58(1), 69-78. https://doi.org/10.1016/j.ymeth.2012.07.008

Ghodke, S., Nielsen, S. B., Christiansen, G., Hjuler, H. A., Flink, J., \& Otzen, D. (2012). Mapping out the multistage fibrillation of glucagon. FEBS Journal, 279(5), 752-765. https://doi.org/10.1111/j.1742-4658.2011. 08465.x

Gratzer, W. B., Bailey, E., \& Beaven, G. H. (1967). Conformational states of glucagon. Biochemical and Biophysical Research Communications, 28(6), 914-919.

Hall-Boyer, K., Zaloga, G. P., \& Chernow, B. (1984). Glucagon: Hormone or therapeutic agent? Critical Care Medicine, 12(7), 584-589.

Hovgaard, M. B., Dong, M., Otzen, D. E., \& Besenbacher, F. (2007). Quartz crystal microbalance studies of multilayer glucagon fibrillation at the solid-liquid interface. Biophysical Journal, 93(6), 2162-2169. https://doi.org/10.1529/biophysj.107.109686

Hrncic, R., Wall, J., Wolfenbarger, D. A., Murphy, C. L., Schell, M., Weiss, D. T., \& Solomon, A. (2000). Antibody-mediated resolution of light chainassociated amyloid deposits. American Journal of Pathology, 157(4), 12391246. https://doi.org/10.1016/S0002-9440(10)64639-1
Isas, J. M., Luibl, V., Johnson, L. V., Kayed, R., Wetzel, R., Glabe, C. G., ... Chen, J. (2010). Soluble and mature amyloid fibrils in drusen deposits. Investigative Ophthalmology and Visual Science, 51(3), 1304-1310. https://doi.org/10.1167/iovs.09-4207

Julian, M. C., Rabia, L. A., Desai, A. A., Arsiwala, A., Gerson, J. E., Paulson, H. L., ... Tessier, P. M. (2019). Nature-inspired design and evolution of anti-amyloid antibodies. Journal of Biological Chemistry. Advance online publication. https://doi.org/10.1074/jbc.RA118. 004731

Kayed, R., \& Glabe, C. G. (2006). Conformation-dependent anti-amyloid oligomer antibodies. Methods in Enzymology, 413, 326-344. https:// doi.org/10.1016/S0076-6879(06)13017-7

Kayed, R., Head, E., Thompson, J. L., McIntire, T. M., Milton, S. C., Cotman, C. W., \& Glabe, C. G. (2003). Common structure of soluble amyloid oligomers implies common mechanism of pathogenesis. Science, 300(5618), 486-489. https://doi.org/10.1126/science.1079469

Kayed, R., Head, E., Sarsoza, F., Saing, T., Cotman, C. W., Necula, M., ... Glabe, C. G. (2007). Fibril specific, conformation dependent antibodies recognize a generic epitope common to amyloid fibrils and fibrillar oligomers that is absent in prefibrillar oligomers. Molecular Neurodegeneration, 2, 18. https://doi.org/10.1186/1750-1326-2-18

Lowe, D., Dudgeon, K., Rouet, R., Schofield, P., Jermutus, L., \& Christ, D. (2011). Aggregation, stability, and formulation of human antibody therapeutics. Advances in Protein Chemistry and Structural Biology, 84, 41-61. https://doi.org/10.1016/B978-0-12-386483-3.00004-5

Oliveira, C. L., Behrens, M. A., Pedersen, J. S., Erlacher, K., Otzen, D., \& Pedersen, J. S. (2009). A SAXS study of glucagon fibrillation. Journal of Molecular Biology, 387(1), 147-161.

Onoue, S., Ohshima, K., Debari, K., Koh, K., Shioda, S., Iwasa, S., ... Yajima, T. (2004). Mishandling of the therapeutic peptide glucagon generates cytotoxic amyloidogenic fibrils. Pharmaceutical Research, 21(7), 1274-1283.

O'Nuallain, B., \& Wetzel, R. (2002). Conformational Abs recognizing a generic amyloid fibril epitope. Proceedings of the National Academy of Sciences of United States of America, 99(3), 1485-1490. https://doi.org/ 10.1073/pnas.022662599

Pedersen, J. S. (2010). The nature of amyloid-like glucagon fibrils. Journal of Diabetes Science and Technology, 4(6), 1357-1367. https://doi.org/ 10.1177/193229681000400609

Pedersen, J. S., \& Otzen, D. E. (2008). Amyloid-a state in many guises: Survival of the fittest fibril fold. Protein Science, 17(1), 2-10. https:// doi.org/10.1110/ps.073127808

Pedersen, J. S., Dikov, D., Flink, J. L., Hjuler, H. A., Christiansen, G., \& Otzen, D. E. (2006). The changing face of glucagon fibrillation: Structural polymorphism and conformational imprinting. Journal of Molecular Biology, 355(3), 501-523. https://doi.org/10.1016/j.jmb. 2005.09.100

Perchiacca, J. M., \& Tessier, P. M. (2012). Engineering aggregationresistant antibodies. Annual Review of Chemical and Biomolecular Engineering, 3, 263-286. https://doi.org/10.1146/annurevchembioeng-062011-081052

Pohl, R., Li, M., Krasner, A., \& De Souza, E. (2015). Development of stable liquid glucagon formulations for use in artificial pancreas. Journal of Diabetes Science and Technology, 9(1), 8-16. https://doi.org/10.1177/ 1932296814555541

Rabia, L. A., Zhang, Y., Ludwig, S. D., Julian, M. C., \& Tessier, P. M. (2019). Net charge of antibody complementarity-determining regions is a key predictor of specificity. Protein Engineering, Design and Selection. Advance online publication. https://doi.org/10.1093/protein/gzz002

Russell, S. J., El-Khatib, F. H., Nathan, D. M., Magyar, K. L., Jiang, J., \& Damiano, E. R. (2012). Blood glucose control in type 1 diabetes with a bihormonal bionic endocrine pancreas. Diabetes Care, 35(11), 21482155. https://doi.org/10.2337/dc12-0071

Russell, S. J., El-Khatib, F. H., Sinha, M., Magyar, K. L., McKeon, K., Goergen, L. G., ... Damiano, E. R. (2014). Outpatient glycemic 
control with a bionic pancreas in type 1 diabetes. New England Journal of Medicine, 371(4), 313-325. https://doi.org/10.1056/ NEJMoa1314474

Shire, S. J. (2009). Formulation and manufacturability of biologics. Current Opinion in Biotechnology, 20(6), 708-714. https://doi.org/10.1016/j. copbio.2009.10.006

Steiner, S. S., Li, M., Hauser, R., \& Pohl, R. (2010). Stabilized glucagon formulation for bihormonal pump use. Journal of Diabetes Science and Technology, 4(6), 1332-1337. https://doi.org/10.1177/ 193229681000400606

Tiller, K. E., Li, L., Kumar, S., Julian, M. C., Garde, S., \& Tessier, P. M. (2017). Arginine mutations in antibody complementarity-determining regions display context-dependent affinity/specificity trade-offs. Journal of Biological Chemistry, 292(40), 16638-16652. https://doi.org/10.1074/ jbc.M117.783837

Tiller, K. E., Chowdhury, R., Li, T., Ludwig, S. D., Sen, S., Maranas, C. D., \& Tessier, P. M. (2017). Facile affinity maturation of antibody variable domains using natural diversity mutagenesis. Frontiers in Immunology, 8, 986. https://doi.org/10.3389/fimmu.2017.00986

Unson, C. G. (2002). Molecular determinants of glucagon receptor signaling. Biopolymers, 66(4), 218-235. https://doi.org/10.1002/bip.10259

Wang, W. (2005). Protein aggregation and its inhibition in biopharmaceutics. International Journal of Phamaceutics, 289(1-2), 1-30. https:// doi.org/10.1016/j.ijpharm.2004.11.014

Ward, W. K., Massoud, R. G., Szybala, C. J., Engle, J. M., Youssef, J. E., Carroll, J. M., ... DiMarchi, R. D. (2010). In vitro and in vivo evaluation of native glucagon and glucagon analog (MAR-D28) during aging: Lack of cytotoxicity and preservation of hyperglycemic effect. Journal of Diabetes Science and Technology, 4(6), 1311-1321. https://doi.org/10. $1177 / 193229681000400604$

White, J. W., \& Saunders, G. F. (1986). Structure of the human glucagon gene. Nucleic Acids Research, 14(12), 4719-4730.

Wu, J. W., Breydo, L., Isas, J. M., Lee, J., Kuznetsov, Y. G., Langen, R., \& Glabe, C. (2010). Fibrillar oligomers nucleate the oligomerization of monomeric amyloid beta but do not seed fibril formation. Journal of Biological Chemistry, 285(9), 6071-6079. https://doi.org/10.1074/jbc. M109.069542

\section{SUPPORTING INFORMATION}

Additional supporting information may be found online in the Supporting Information section at the end of the article.

How to cite this article: Stimple SD, Kalyoncu S, Desai AA, et al. Sensitive detection of glucagon aggregation using amyloid fibril-specific antibodies. Biotechnology and Bioengineering. 2019;116:1868-1877.

https://doi.org/10.1002/bit.26994 